\title{
Petersen-hernia, egy ritka sérvtípus megjelenése osztályunkon
}

\section{Petersen hernia, a rare type of hernia in our department}

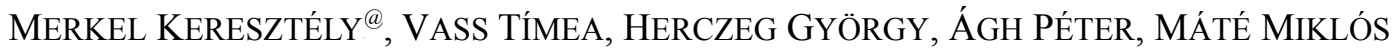 \\ Szent Imre Kórház, Általános Sebészeti Profil (profilvezető főorvos: dr. Máté Miklós PhD)
}

\begin{abstract}
61 éves nőbeteg anamnéziséből 3 évvel korábbi, morbid obezitás miatti bariátriai mütét (Roux Y gastric bypass, műtét előtti BMI 42, aktuális BMI 22), hysterectomia, hypertonia említendő. Négy napja tartó diffúz hasi fájdalom, hányás, hányinger, székletkimaradás miatt került SBO érintésével sebészeti osztályunkra. Felvételkor mérsékelt hasi distenzió, diffúz felhasi 3-5/10 fájdalom volt, defensus nélkül, NG szonda jelentős tartalmat nem hozott. Ileusra jellemző auscultációt, rectalis vizsgálattal üres ampullát találtunk. Álló natív hasi felvételen jobb oldalon L II-III. csigolya mellett kissé gázos, nem tágabb vékonybélkacs került leírásra, benne 2-3 cm-es nívóval. Hasi UH-vizsgálaton folyadékkal telt, tág, 30-35 mm átmérőjü vékonybeleket írtak le. CT-vizsgálat során a duodenum, jejunum és néhány proximalis ileumkacs kóros distensióját igazolták, nívókkal, innen aboralisan összeesett vékonybeleket.

Tekintettel a kliniko-radiológiai képre, urgens mütét során Hasson-technikával laparoszkópos inspekciót végeztünk, azonban a masszív ileus okozta térhiány miatt kp medián laparotómiára konvertáltunk. Az exploráció során a Petersen-hernián át a jobb hasfélbe herniálódott alimentáris, biliopancreatikus és közös vékonybélszakaszt észleltünk a terminális ileum közepéig. A bél életképesnek bizonyult. A Petersen-hernián át a kizáródott szakaszt a bal hasfél felé visszahelyeztük, majd a Petersen-herniát nem felszívódó fonallal a colon transversum és az alimentáris kacs mezentériuma közt tovafutó varrattal zártuk. A beteg az ötödik postoperatív napon gyógyultan távozott.
\end{abstract}

Kulcsszavak: Petersen-hernia, morbid obezitás, laparoszkópos Roux Y gyomor bypass

61 years old female with previous surgical history of Roux-en-Y gastric bypass (3 years ago) and earlier hysterectomy admitted to our surgical department with clinical and radiological signs of small intestinal obstruction. Urgent intervention had been performed with following findings: Petersen herniation of alimentary tract including the - biliopancreatic tract and the small bowel extending to the midpart of the terminal ileum. Viability of herniated intestinal tract had been confirmed, and reposition of herniated parts through the Petersen hernia had been done. Closure with non-absorbable running suture of the gap between the transverse colon and the mesenteriun of the alimentary limb had been performed. Patient was fit for discharge on the fifth postoperative day.

Keywords: Petersen hernia, morbid obesity, laparoscopic Roux-en-Y gastric bypass

Beérkezett: 2021. április 29.; elfogadva: 2021. május 26.

\section{Bevezetés}

A gastrojejunostomiát igénylő beavatkozások számának csökkenésével, a Petersen-hernia a legtöbb sebész számára az elmúlt évtizedekben egy elfelejtett diagnózis. A morbid obezitás miatt végzett Laparoscopos Roux Y Bypass (LRYGBP) műtétek számának növekedésével azonban növekszik e ritka hernia incidenciája is. Korai felismerése nagyban csökkenti a morbiditást és mortalitást. A Petersen-tér primer zárása jelentősen csökkenti e belső hernia kialakulásának kockázatát. A Petersen-hernia először 1900ban került leírásra dr. Walter Petersen német sebész által, mint belső sérv, bármely típusú gastrojejunostomia után (leggyakrabban Roux Y anastomosist követően). Határait a mesocolon transversum, a retroperitoneum és a Roux-kacs mezentériuma alkotja ${ }^{1}$ (1. ábra). Ez a belső sérv korábban nagyon ritka volt, 1974-ig mintegy 178 esetet írtak le világszerte, ${ }^{2}$ bár ez az incidencia valószínüleg alulértékelt. Gyakoribbá vált az 1960-as, 1970-es években a peptikus fekély miatt végzett mütétek számának emelkedésével. Ex-

\footnotetext{
@Levelezési cím/Corr. address: Dr. Merkel Keresztély, 1028 Budapest, Bethlen Gábor u. 28., Tel.: +36 309637535 ,

E-mail: kmerkel1@gmail.com
} 
ponenciális növekedést a bariátriai laparoszkópos Roux Y Gastric Bypass mütétek megugrásával észleltünk. ${ }^{3-12}$ Ezért a mütétek során gondolni kell e tér primer lezárására, bár jelentős mesenteriális zsírveszteség után a Petersen-hernia bizonyos részei zárást követően is megnyílhatnak.

\section{Esetismertetés}

61 éves nőbeteg anamnéziséből 3 évvel korábbi, morbid obezitás miatti bariátriai mütét (Roux Y Gastric Bypass, mütét elötti BMI 42, aktuális BMI 22), hysterectomia, hypertonia említendő. Négy napja tartó diffúz hasi fájdalom, hányás, hányinger, székletkimaradás miatt került SBO érintésével sebészeti osztályunkra. Felvételkor mérsékelt hasi distenzió, diffúz felhasi 3-5/10 fájdalma volt, defensus nélkül, NG szonda jelentős tartalmat nem hozott. Ileusra jellemző auscultációt, rectalis vizsgálattal üres ampullát találtunk. Álló natív hasi felvételen jobb oldalon L II-III.

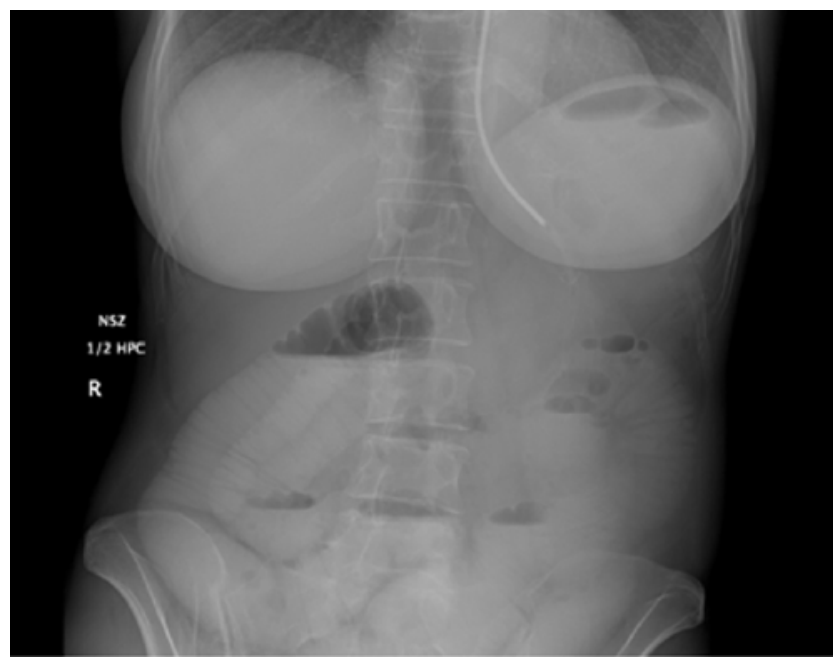

1. ábra. Natív hasi röntgenfelvétel

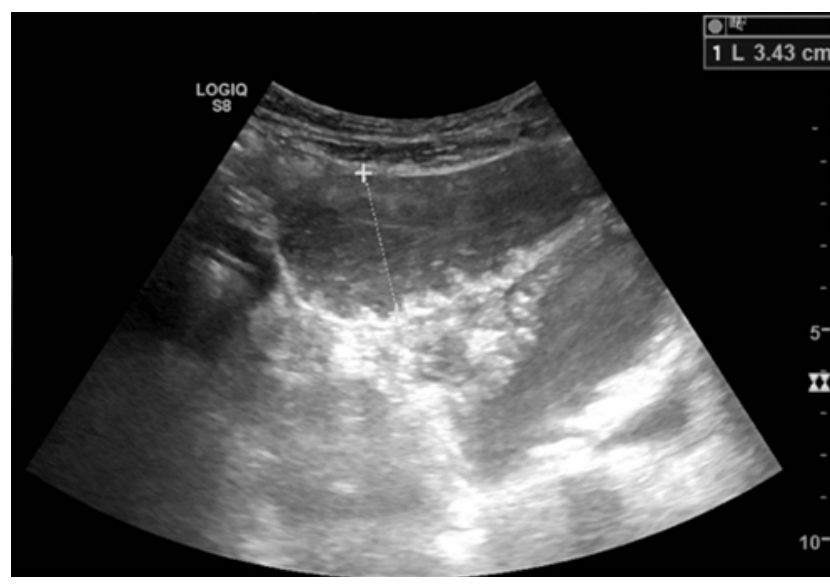

2. ábra. UH-vizsgálat

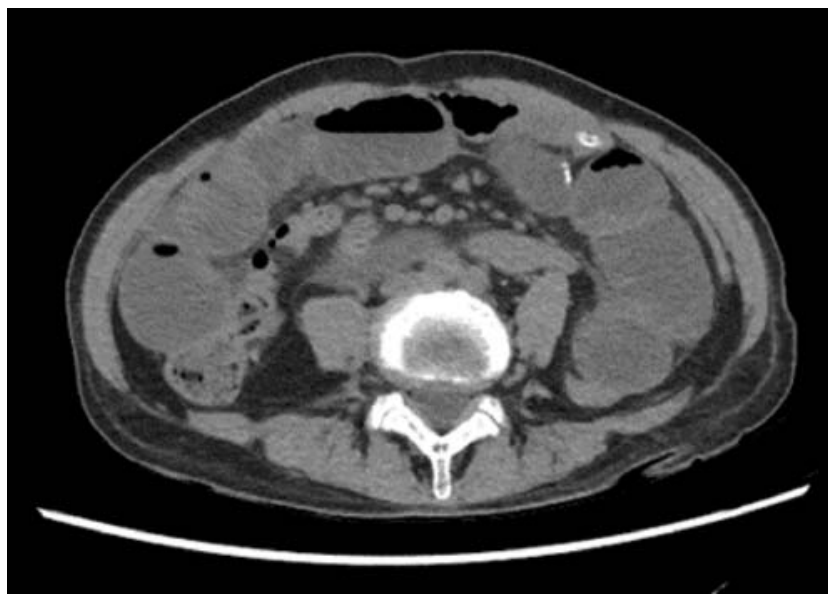

3. ábra. Hasi CT-vizsgálat

csigolya mellett kissé gázos, nem tágabb vékonybélkacs került leírásra, benne 2-3 cm-es nívóval (1. ábra). Hasi UH-vizsgálaton folyadékkal telt, tág, 30-35 mm átméröjü vékonybeleket írtak le (2. ábra). CT-vizsgálat során a

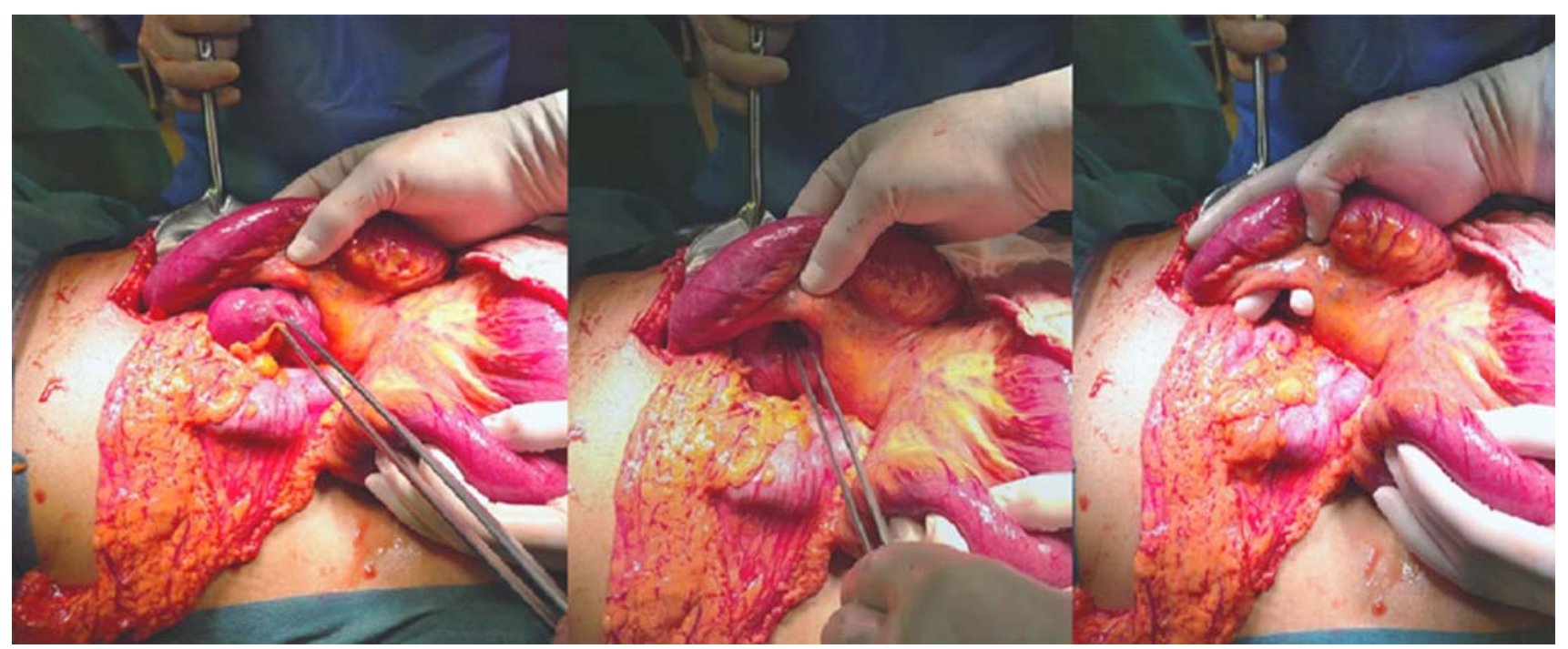

4. ábra. Intraoperatív fotó, a bél repozíciója, illetve a Petersen-hernia képe 
duodenum, jejunum és néhány proximalis ileumkacs kóros distensióját igazolták, nívókkal, innen aboralisan összeesett vékonybeleket (3. ábra).

Laborjában leukocytosison $(15,28 \mathrm{G} / \mathrm{L})$ kívül érdemi kórjelző nem volt.

Tekintettel a kliniko-radiológiai képre, sürgős mütét során Hasson-technikával ${ }^{13}$ laparoszkópos inspekciót végeztünk, azonban a masszív ileus okozta térhiány miatt kp medián laparotómiára konvertáltunk. Az exploráció során a Petersen-hernián át a jobb hasfélbe herniálódott alimentáris, biliopancreatikus és közös vékonybélszakaszt észleltünk a terminális ileum közepéig. A bél életképesnek bizonyult. A Petersen-hernián át a kizáródott szakaszt a bal hasfél felé visszahelyeztük (4. ábra), majd a Petersenherniát nem felszívódó fonallal a colon transversum és az alimentáris kacs mesenteriuma közt tovafutó varrattal zártuk. A beteg az ötödik postoperatív napon gyógyultan távozott.

\section{Diszkusszió}

Bármely típusú gastrojejunalis anastomosist követően potenciálisan megnyílik egy tér, mely belső sérv kialakulásához vezethet.

A Petersen-hernia modern definíciója kissé különbözik az eredetitől, 2,13,14 mely eredetileg Loop Gastrojejunostomia után óra járásával megegyező rotációval és efferens kacs herniálódással került közlésre.

A modern felfogás szerint a határokat a mesocolon transversum alsó éle, az alimentáris kacs és a retroperitoneum alkotja, és ide záródhat ki a vékonybél. ${ }^{2,5,9}$ A laparoszkópia világos előnyei mellett a növekvő bariátriai aktivitással (LRYGB) növekszik a belső sérvek okozta vékonybél kizáródások száma. ${ }^{7}$ Laparoszkópos beavatkozás után az adhaesiók relatív hiánya hozzájárul a vékonybél nagyobb mobilitásához és a belső herniák kialakulásához. ${ }^{12,16}$ A nyitott Roux Y mütéteknél gyakoribb az adhaesiós ileus ${ }^{5}$ és minimális a belső sérv okozta kizáródás. A belső sérvek előfordulása LRYGB után 1-4\%, ${ }^{6,16}$ míg nyitott mütétek után ritka $^{12}$ (kevesebb mint $1 \%$ ).

Több tanulmány szerint az antecolicus Roux kacs alacsonyabb belső sérv incidenciával jár, ${ }^{10,11,16}$ de vannak ennek ellentmondó tanulmányok. ${ }^{9}$ Egyes közlemények szerint a leggyakoribb belsősérv-kialakulás közül az antecolicus RYGB után a Petersen-hernia, más tanulmányok a RYGB után a belső sérvek előfordulását tekintve első helyen a jejuno-jejunalis anastomosisszal kapcsolatos intermesenterialis herniációt emelik ki, a Petersen-sérv második helyen áll, amennyiben antecolicusan kialakított alimentaris kacsról van szó. ${ }^{8,9}$ Konszenzus napjainkban, hogy a mezentériumdefektust tovafutó varrattal kell zárni, 9,12,17 lehetőleg nem felszívódó fonallal, de teljesen így sem eliminálható a rizikó, mivel a morbid obezitás miatt végzett mütétek után a masszív mezenteriális zsírvesztés kitágítja és adekvát primer zárás esetén is megnöveli a kis mezentériumdefektusok lehetőségét. 6,8

\section{Következtetések}

A kihívás ezeknél a betegeknél, hogy a hasfájás-hányás mellett sok esetben nem specifikus vagy nem diagnosztikus a radiológiai kép. ${ }^{5,11}$ A diagnosztikus nehézséget fokozza, hogy a tünetekkel jelentkező páciensek $20 \%$-ánál az elvégzett kontrasztanyagos képalkotó vizsgálatok teljesen negatívak. A betegek leginkább étkezést követő görcsös hasi fájdalmat és hányingert panaszolnak. A csak biliopankreatikus kacsot érintő kizáródás esetén (75-115 cm hosszú kacs az obezitás miatt végzett LRYGB esetén) az alimentáris kacson és a közös kacson át a passage biztosított, így sok esetben a kizáródás hosszú időn át rejtve marad, az esetek 20-30\%-ában normál labor paraméterek és normál radiológiai kép mellett alakul ki, ezért kétség esetén a korai diagnózishoz mindenképp javasolt a korai hasi CT-vizsgálat és a korai exploratív laparoszkópia a bélnekrózis elkerülése érdekében, mivel ebben az esetben magas a mortalitás és a morbiditás. ${ }^{12,16}$. A hasi CT-vizsgálat típusosan jejunalis szakaszra lokalizálódó ileus képét mutatja, amely megerősíti a mütéti indikációt. Iv. kontrasztanyag adásával kiegészített CT-vizsgálat ilyenkor segítséget jelenthet az „örvény jel” észlelésével, amelyet Petersen-sérv esetén az alimentaris kacs mezenteriális erei körül a herniálódott vékonybél mezentériuma okoz, patognómikus a belső sérv vonatkozásában. Korai diagnózis esetén a betegek többsége laparoszkóppal kezelhető a hernia reductiójával és a mezenteriális defektus zárásával. A sürgősségi ellátásban részt vevő kollegák figyelmét érdemes felhívni erre a ritka, de egyre gyakoribb sérvtípusra.

\section{Irodalomjegyzék}

${ }^{1}$ Petersen W: Über Darmverschlingung nach der GastroEnterostomie. Arch Klin Chir 1900; 62: 94-114.

${ }^{2}$ Rogers AM, Ionescu AM, Pauli EM, Meier AH, Shope TR, Haluck RS: When is a Petersen's hernia not a Petersen's hernia. J Am Coll Surg. 2008; 207: 121-124.

3 Johnson JM, Wood M, Lawson J, Hale HW, Jr: Retroanastomotic hernia. Arch Surg 1974; 108: 363-365.

${ }^{4}$ Fineberg HV, Pearlman LA: Surgical treatment of peptic ulcer in the United States. Trends before and after the introduction of cimetidine. Lancet 1981; 1: 13051307.

${ }^{5}$ Morgan H, Chastanet R, Lucha PA: Internal hernia after laparoscopic gastric bypass surgery: a case report and literature review. Postgrad Med 2008; 120: E01-E05.

${ }^{6}$ Paroz A, Calmes JM, Giusti V, Suter M: Internal hernia after laparoscopic Roux-en-Y gastric bypass for morbid obesity: a continuous challenge in bariatric surgery. Obes Surg 2006; 16: 1482-1487.

${ }^{7}$ Cho M, Pinto D, Carrodeguas L, Lascano C, Soto F, Whipple $O$ : Frequency and management of internal hernias after laparoscopic antecolic antegastric Roux-en-Y gastric bypass without division of the small bowel mesentery or closure of mesenteric defects: review of 1400 consecutive cases. Surg Obes 2006; 2: 87-91. 
${ }^{8}$ Comeau E, Gagner M, Inabnet WB, Herron DM, Quinn TM, Pomp A: Symptomatic internal hernias after laparoscopic bariatric surgery. Surg End 2005; 19: 34-39.

${ }^{9}$ Carmody B, DeMaria EJ, Jamal M, Johnson J, Carbonell A, Kellum $J$ : Internal hernia after laparoscopic Roux-en-Y gastric bypass. Surg Obes 2005; 1: 543-548.

${ }^{10}$ Champion JK, Williams M: Small bowel obstruction and internal hernias after laparoscopic Roux-en-Y gastric bypass. Obes Surg 2003; 13: 596-600.

11 Garza E, Kuhn J, Arnold D, Nicholson W, Reddy S, McCarty T: Internal hernias after laparoscopic Roux-en-Y gastric bypass. Am J Surg 2004; 8: 796-800.

12 Higa KD, Ho T, Boone KB: Internal hernias after laparoscopic Roux-en-Y gastric bypass: incidence, treatment and prevention. Obes Surg 2003; 13: 350-354.

${ }^{13}$ George R, Veerabhadra R, Mebin M, Ashwini T, Rahman $A$ : Modified Hasson technique: a quick and safe entry of first port into the abdomen. Int Surgery Journal 2019; 8: 2802-2805.

${ }^{14}$ Sebesta DG, Robson MC: Petersen's retroanastomotic hernia. Am J Surg 1968; 116: 450-453.
${ }^{15}$ Rutledge $R H$ : Retroanastomotic hernias after gastrojejunal anastomoses. Ann Surg 1973; 177: 547-553.

${ }^{16}$ Franke M, Tennstedt A: So-called Petersen's hernia following gastroenterostomies. Zentralblatt für Allgemeine Pathologie und Pathologische Anatomie 1972; 115: 335340.

${ }^{17}$ Parakh S, Soto E, Merola S: Diagnosis and management of internal hernias after laparoscopic gastric bypass. Obes Surg 2007; 17: 1498-1502.

${ }^{18}$ Higa K, Boone K, Arteaga GI, López-Tomassetti FE: Mesenteric closure in laparoscopic gastric bypass: surgical technique and literature review. Cirugía Española 2007; 82: 77-88.

${ }^{19}$ Srikanth MS, Keskey T, Fox SR, Oh KH, Fox ER, Fox $K M$ : Computed tomography patterns in small bowel obstruction after open distal gastric bypass. Obes Surg 2004; 14: 811-822.

${ }^{20}$ Ximenes MAS, Baroni RH, Trindade RMC, Racy MCJ, Tachibana A, Moron RA: Petersen's hernia as a complication of bariatric surgery: CT findings. Abdominal Imaging 2010; 36(2): 126-129.

A cikk a Creative Commons Attribution 4.0 International License (https://creativecommons.org/licenses/by/4.0/) feltételei szerint publikált Open Access közlemény, melynek szellemében a cikk bármilyen médiumban szabadon felhasználható, megosztható és újraközölhetö, feltéve, hogy az eredeti szerző és a közlés helye, illetve a CC License linkje és az esetlegesen végrehajtott módosítások feltüntetésre kerülnek. (SID_1) 